\section{Experiências de ensino integrado}

a nivel de graduação;

2. Experiências de ensino integrado a nivel de pós-graduaçāo.

Carmem Catarina Handel *

* Professora da Universidade Federal do Rio Grande do Sul, Chefe do Departamento de Ciências Administrativas do Programa de Pós-Graduação em Administração.
Este trabalho tem a intenção de relatar algumas experiências no campo de metodologia do ensino de administração, realizadas na Universidade Federal do Rio Grande do Sul, com base no conceito de ensino integrado.

Consideramos integraf̧ão o estabelecimento de relações entre experiências de aprendizagem, em torno de um problema, situação, objetivo ou conceito-chave, de forma que os estudantes tenham a oportunidade de adquirir uma visão mais completa e significativa dos conteúdos apresentados pelas diferentes disciplinas, ou pelas diferentes unidades de uma mesma disciplina, o que lhes trará, em conseqüência, um comportamento mais adequado à realidade.

No desenvolvimento deste trabalho, optamos pela separação em curso de graduação e curso de pós-graduação, tendo em vista as características de cada um, especialmente no que diz respeito à elaboração de currículos. Como se sabe, os cursos de pós-graduação têm mais flexibilidade e facilidade para a atualizaçăo curricular, dentre outras condições que os diferenciam dos de graduação.

A nível de graduação, relataremos uma experiência efetuada em uma das disciplinas do curso, e uma segunda, constituída por atividade desenvolvida pelo Departamento de Ciências Administrativas, que se formalizou em um roteiro para elaboração de planos de ensino.

A nível de pós-graduação, relataremus experiências relativas a diferentes tipos de integração: integração de todas as atividades do curso em torno dos objetivos gerais do mesmo; integração realizada pelo aluno por meio do que está sendo chamado "estudo individualizado", integração das dimensőes humana e técnica e entre atividades de ensino e pesquisa.

Finalizando o trabalho, teceremos alguns comentários sobre o embasamento teórico das experiências relatadas.

\section{EXPERIENCIAS DE ENSINO INTEGRADO A NIVEL DE GRADUAÇÃO}

Inicialmente, relataremos a experiência realizada por um dos professores da disciplina chamada análise administrativa. Este professor desenvolveu seu trabalho em torno de conceitos-chave e de resultados finais determinados para a disciplina. A partir do conceito, ou em torno deste, é que o trabalho é desenvolvido. $O$ professor organiza a situação para que os estudantes, ao final de determinado período, sejam capazes de construir instrumentos e tomar decisões quanto à aplicação dos mesmos. Algumas perguntas são colocadas como estímulo inicial. O que é? Para que serve? Como se faz? Para que se usa? E outras semelhantes. $O$ papel deste professor é tipicamente o de administrador da situaçāo de aprendizagem. Ele fixa os objetivos e coloca à disposição dos alunos todo o material que pode ser utilizado, incluindo-se a si próprio, para que sejam atingidos os resul- 
tados desejados. O horário é flexível, uma vez que a ênfase está no produto e no processo e não em uma estrutura prefixada e rígida. Além dos livros disponíveis sobre o assunto, os estudantes contam com um texto elaborado pelo professor e com ele próprio como pessoa-fonte, sempre em disponibilidade para responder perguntas, esclarecer dúvidas, etc. Este professor só faz exposiçōes, muito curtas, para introduzir unidades, responder perguntas comuns a vários alunos, ou para, quando julgar necessário, conduzir ao fechamento da situação. Consideramos este caso como de integração especialmente intradisciplinar, embora saibamos que ocorre também integração interdisciplinar, com as disciplinas de introdução à administração, teoria geral de administração e outras. Caracterizamos a presente como experiência de ensino integrado, porque: a) os objetivos são formulados e, em conseqüềncia, são mobilizados conteúdos, os quais são agrupados e organizados em torno de cada objetivo; $b$ ) a metodologia ou os procedimentos são escolhidos de acordo com as situaçðes, ou as necessidades de cada situação. Poderíamos dizer que a abordagem é sistêmica e que é utilizado sistema modular de ensino, aplicando-se princípios de ensino para a competência e ensino programado. Uma vez que o trabalho é. desenvolvido para que todos atinjam todos os objetivos, o ritmo de cada aluno é respeitado e o aluno tem conhecimento imediato dos resultados, podendo realizar os ajustamentos ou correções necessárias; $c$ ) a avaliação é contínua e sistemática - o professor realiza o acompanhamento de cada aluno durante o desenvolvimento de cada etapa do trabalho, dando feed-back e realizando o controle e a avaliação com referência aos objetivos, aos processos e aos recursos.

A segunda experiência constitui uma tentativa de integração feita por meio da elaboração de planos de ensino a partir de um roteiro preestabelecido. Para tal, tomou-se como base o modelo geral de ensino, que foi organizado através de contribuiçð̋es de Cagné, Glaser e Popham. Esse modelo se compõe de quatro elementos: objetivos, pré-requisitos, procedimentos de ensino e avaliação, os quais se relacionam funcionalmente. Consideramos que esse roteiro poderia contribuir para aumentar a efiććcia do ensino, orientando não só o planejamento, mas a implantação e avaliação do mesmo. Acreditamos que, a partir daí, os professores teriam melhores condiçə̃es para organizar a situação de ensino e estabelecer as relaçбes necessárias entre os diferentes componentes do processo de ensino. Com isso, cada professor foi estimulado a clarificar os objetivos ou resultados finais a serem atingidos em sua disciplina. Somente esse fator já colaborou para que um determinado nível de integração fosse alcançado, uma vez que os objetivos determinaram o tipo de organização do ensino, os recursos a serem utilizados e os subsistemas de avaliação. Nossa previsão é que a utilização do plano de ensino elaborado nesses moldes, como instrumento de trabalho docente, provocará um outro tipo de integração pela verificação de objetivos comuns a grupos de disciplinas, qual seja, uma integração interdisciplinar.

\section{EXPERIENCIAS DE ENSINO INTEGRADO A NÍVEL DE PÓS-GRADUAÇÃo}

No mestrado em administração nosso esforço foi e é no sentido de conseguirmos uma clara definição dos resultados a atingir. Estamos certos de que, a partir da clarificação do produto final, ter-se-á condições de mobilizar conteúdos, programar experiências de aprendizagem e determinar o sistema de avaliação. Essa integração a partir dos objetivos gerais do ensino diz respeito tanto à formação do professor do ensino superior como do pesquisador ou técnico de alto padrão. Nosso ponto de vista é o de que certas habilidades ou atitudes são comuns a esses três profissionais. Consideremos, por exemplo, a função de planejamento, a habilidade de trabalhar em equipe $e$ a habilidade de solucionar problemas e de tomar decisões como necessárias ao desempenho das atividades daqueles profissionais. Como consequeência desse pressuposto, as disciplinas são planejadas no sentido de promover o desenvolvimento das habilidades mencionadas, bem como de outras, como por exemplo: resultados de pesquisas nos dizem que um executivo gasta a grande maioria de seu tempo em comunicação oral com outras pessoas. Ao constatarmos isso como uma realidade de nosso meio, devemos de alguma forma. desenvolver essa habilidade. Planejamos, assim, além dos seminários, relatos de atividades e outros exercícios cooperativamente com os alunos, atividades extra-classe que representam uma tentativa de atender a essa necessidade.

A estrutura do curso de mestrado, coerente com o princípio de integração, a partir dos objetivos gerais formulados, é definida da seguinte forma:

a) núcleo fundamental: que visa capacitar o aluno nas técnicas inerentes às funções administrativas, as quais serão, em seu conjunto, o verdadeiro campo de atuação profissional do futuro mestre. Esse núcleo fundamental compre-se de um conjunto de disciplinas obrigatórias, que constitui a área básica, e um conjunto de disciplinas optativas, que define uma área de concentração. $O$ núcleo fundamental é o ponto de ingresso de um sistema de formação do administrador de alto nível, do professor universitário e do pesquisador em ciências administrativas. Deste ponto de ingresso, constituído pelas áreas clássicas de finanças, recursos humanos, tecnologia operacional e mercadologia, parte $O$ aluno para 0 aprofundamento teóricoprático nas funçōes administrativas. As áreas e as funçб̄es administrativas se integram através de seminários e estudo de casos administrativos.

b) áreas de aplicação: ${ }^{1}$ complementando os conhecimentos adquiridos no núcleo fundamental, opta $o$ aluno por uma dentre as cinco áreas de aplicação. $O$ objetivo dessas áreas de aplicação é capacitá-lo no trato com os problemas inerentes a um determinado tipo de sistema, com os profissionais aí encontráveis e com as técnicas por eles habitualmente utilizadas. Constituem-se áreas de aplicação os seguintes tipos de sistemas: 
- organizacionais - todo e qualquer tipo de empresa, seja privada ou pública, devotada à produção de bens ou serviços. Enquadram-se nesta classificação genérica, além de praticamente todo o setor privado da economia, todas as instituições de administração indireta do setor público.

- urbanos - todo e qualquer tipo de entidade, privada ou pública, devotada ao estudo, equacionamento ou soluçâo dos problemas urbanos. Enquadram-se aqui toda a administração direta municipal, parte da administração direta estadual e federal do pais e uma gama imensa de empresas consultoras do setor privado ou prestadoras de serviços.

- rurais - todo e qualquer tipo de entidade, privada ou pública, devotada ao estudo, equacionamento ou solução de problemas rurais. Enquadram-se aqui toda a administração direta municipal, parte da administração estadual e federal do país e um variado espectro de empresas consultoras e prestadoras de serviços do setor privado, tais como cooperativas de produção rural, agências de crédito rural, etc.

- regionais - todo e qualquer tipo de entidade, privada ou pública, devotada ao estudo, equacionamento ou solução de problemas regionais - entendida uma região como uma área geográfica suficientemente grande para abarcar subáreas rurais; como tal, enquadram-se as microrregióes, conforme definição do IBGE, os estados, as macrorregiōes, as bacias hidrográficas, as regiões economicamente homogêneas, etc., até o próprio país. Compreende-se aqui, além da administração direta federal, a estadual e a própria administração direta municipal, as regióes metropolitanas, as associações de municípios, as superintendências de desenvolvimento regional e uma extensa gama de empresas consultoras e prestadoras de serviços do setor privado.

- internacionais - todo e qualquer tipo de entidade, pública ou privada, devotada ou envolvida em relacionamento internacional. Enquadram-se aqui não apenas os setores normativos e fiscalizadores - inerentes ao setor público da atividade privada - como também todas as empresas privadas devotadas a qualquer modalidade de comércio internacional que precisem submeter-se àquelas normas. Compreende-se nesta área também toda a instituição não devotada a operações de comércio, mas voltada ao relacionamento internacional, no seu mais amplo sentido, como, por exemplo, as próprias organizações internacionais.

Confiamos que esta estrutura possibilite um crescente nível de integração que culminará com a elaboração da dissertação por parte do aluno. $O$ programa prevê dois tipos de dissertação: dissertação-pesquisa e dissertaçãoprojeto.

O Programa de Pós-Graduação em Administração, considerando as características dos alunos no que se refere à capacidade de autodireção e estudo independente, bem como a expectativas e motivos de desenvolvimento pessoal e profissional, coerente ainda como as características de flexibilidade e princípio de ensino integrado que o norteia, oferece a modalidade de estudos individualizados. Essa modalidade de ensino e aprendizagem se fundamenta em pressupostos de aprendizagem andragógica. Como conseqüência, é iniciada pelo aluno, que deve identificar um problema, necessidade ou interesse e apresentá-lo a um professor orientador com a sua justificativa. A técnica utilizada é a do tutoramento; portanto, o professor, consensualmente com o aluno, detalha o plano de trabalho que deverá ser aprovado pela Comissão Coordenadora do Curso. A duração prevista deste trabalho é de dez semanas e o aluno receberá pelo mesmo três (3) créditos por ele. A integração é caracterizada, neste caso, pela convergência de atividades e conteúdos em direção ao problema, interesse ou necessidade manifestados pelo aluno e que deram origem ao trabalho. $O$ principal critério para avaliação do trabalho resultante desta forma de ensino e aprendizagem é que seja o mesmo publicável, devendo comportar obrigatoriamente algo pessoal do aluno. Os critérios são estabelecidos pelo professor e pelo aluno, cooperativamente.

Quanto à integração entre dimensão humana e técnica dos futuros administradores, desenvolvemos, no início do programa, uma atividade que está sendo rotulada como integração comportamental. Essa atividade tem como objetivo geral clarificar objetivos pessoais dos alunos e aumentar seu autoconhecimento. As questões colocadas são:

- Quais são suas expectativas com relação ao curso?

- Que resultados deseja atingir?

- Quais são seus recursos pessoais quanto a: tempo, experiências, conhecimentos, finanças, habilidades, características pessoais e recursos grupais?

- Relacionamento objetivo e organização do curso com seus objetivos e condiçōes.

- Inventário de tempo.

- Objetivos de vida.

Esta atividade está tendo continuidade por meio de reuniōes com professores e coordenação - algumas formais, outras informais - de confraternização.

Quanto à integração ensino-pesquisa, a orientação é no sentido do aproveitamento de atividades de pesquisas para a aprendizagem, tanto como exigência da disciplina pesquisa em administração, como desenvolvimento de projetos por professores e alunos. Por outro lado, esperamos que o professor realize um determinado tipo de pesquisa, ainda que seja a utilização de procedimentos científicos para aperfeiçoamento do próprio desempenho.

Apresentamos, a seguir, o quadro teórico de referência que embasa as experiências descritas. Constitui-se o mesmo de pressupostos sobre o processo de aprendizagem andragógica e, especificamente, sobre o ensino integrado. Como princípios orientadores do ensino integrado, podemos enumerar: 
- Um mesmo objetivo pode ser atingido por diferentes tipos de experiências de aprendizagem, desde que obedeçam a padróes de aprendizagem significativas.

- Uma única experiência de aprendizagem poderá atingir objetivos diversos, dependendo das condiçðes individuais de cada aluno e das condiçðes do professor.
- O papel da experiência do estudante é um recurso importante para a aprendizagem.

Os pressupostos de aprenđızagem andragógica utilizados são apresentados a seguir; dizem respeito às características do adulto e suas implicaçðes no processo de aprendizagem.

\section{Características do adulto}

1. O adulto tende a se ver como personalidade responsável e autodirigida. Necessita ser tratado com respeito e ser percebido como tendo a habilidade de dirigir sua vida.

2. O adulto, com algum auxílio, é capaz de diagnosticar suas próprias necessidades de aprendizagem.

3. O adulto pode colaborar no planejamento e condução do processo de aprendizagem.

4. O aprendiz adulto pode avaliar os resultados de sua aprendizagem.

5. Cada adulto entra na situação de aprendizagem com um certo background de experiências. Ele não teve somente um grande número de experiências, como uma variedade em termos de tipos.

6. O adulto participa de uma situação de aprendizagem em resposta a pressōes e problemas de sua vida. Sua perspectiva de tempo é a de aplicação imediata. Ele vê a aprendizagem como um processo de aperfeiçoamento de suas habilidades em lidar com problemas que enfrenta no presente. Ele tende a participar de situaçōes de aprendizagem que são solicitadas no problema.
Implicaçōes

Ê dada mais atenção ao ambiente de aprendizagem. É importante um clima de respeito entre aprendiz e professor. A situação de aprendizagem deve ser amigável e informal.

Os treinadores de adultos devem ter a habilidade de criar situaçōes não-ameaçadoras. Necessidades decorrentes da experiência do professor e aquelas colocadas pela organização devem ser negociadas com o treinando.

Uma situaģão de aprendizagem para um adulto pode ser constituŕda de encontros de grupos pequenos e de desenvolvimento de projetos, onde cada participante é auxiliado pelos outros e os auxilia.

O professor não julga o desempenho por seus critérios, mas auxilia o grupo a criar recursos e procedimentos para coletar evidências do progresso feito e avaliá-lo.

Os adultos são um recurso importante para a aprendizagem dos outros. Eles são menos dependentes do professor e dos livros. A nova aprendizagem acontece mais facilmente devido à amplitude de experiências passadas que a embasam e com as quais pode ser relacionada.

O ponto inicial da situação pode ser um problema ou uma dificuldade que os participantes do programa trazem consigo. Talvez a melhor pergunta inicial seja: o que você espera levar deste programa? Uma das primeiras atividades talvez seja um levantamento de problemas ou um exercício de diagnóstico através do qual os participantes identifiquem problemas específicos para os quais desejem auxílio.
Além destes, trabalhamos com um pressuposto que nos parece dos mais relevantes, isto é, que a utilização de uma ou várias técnicas depende de algumas variáveis como:

- características pessoais do professor. Exemplo: um professor muito organizado terá dificuldades para um ensino não-diretivo;

- domínio que o professor tem da técnica;

- relação da técnica com um ou mais objetivos;

- condiçð̋es de tempo; espaço; número de alunos; recursos financeiros;

- natureza da disciplina.
Mais uma vez, enfatizamos que nossa preocupação é com o produto. É a partir de sua definição que nos preocupamos com processos, recursos, condiçōes de matériaprima e controle de qualidade.

Embora não tenhamos ainda realizado um estudo mais rigoroso que nos diga dos resultados reais da aplicação da metodologia aqui descrita, os dados colhidos por instrumentos de medida para a avaliação nos dizem que devemos continuar em direção ao aperfeiçoamento desta metodologia.

1 Extraído do documento básico do Programa de Pós-Graduação em Administração, $2 .^{\circ}$ semestre de 1975. 